\title{
AN EARTHQUAKE ALARM SYSTEM FOR THE MAUI A OFFSHORE PLATFORM, NEW ZEALAND
}

\author{
By R. G. Tyler and J. L. BeCk
}

\begin{abstract}
An earthquake alarm system for the Maui A Offshore Platform, which is situated in the Tasman Sea off the coast of New Zealand for the production of natural gas, is described. The function of the alarm system is to give an immediate warning when accelerations equal to half the design level for the platform have been reached in order that safety procedures can be initiated. The alarm system was designed to monitor only the response of the lower modes of the platform, as these would make the major contribution to the stresses in the platform. Ambient vibration measurements were performed which showed the values of frequency for the six lowest modes to be in the range of 0.45 to $1.35 \mathrm{~Hz}$. The alarm system was accordingly designed so that the signal from the transducers passed through a filter with a nominally flat frequency response over a bandwidth 0.3 to $2 \mathrm{~Hz}$ with a sharp roll-off at $24 \mathrm{~dB}$ per octave at higher frequencies. A radio link with similar detectors on shore was arranged to give confirmation that an earthquake had occurred in order to reduce the risk of false alarms.
\end{abstract}

\section{INTRODUCTION}

The Maui A Offshore Platform (Figure 1), which commenced production in May 1979, is operated by Shell BP Todd Ltd. primarily for the production of natural gas. It is situated in the Tasman Sea, $37 \mathrm{~km}$ off the Taranaki Coast, New Zealand. The height of the tower, from the sea bed to the base of the platform, is $122 \mathrm{~m}$. Gas from the platform is piped ashore to the base at Oaonui and, after processing to outlets throughout the North Island of New Zealand, it will ultimately form the basis of a petrochemical industry which is at present being developed in New Zealand. Because of its importance to the economy of the country, special attention to the monitoring of earthquakes affecting the platform has been given by the Engineering Seismology Section, Physics and Engineering Laboratory, Department of Scientific and Industrial Research, which is also responsible for the operation of the New Zealand Strong-Motion Recording Network (Hefford et al., 1979).

\section{SEISMICITY}

The Maui A Platform is situated on the edge of the main seismic region of New Zealand, which extends as a broadband through the South and the North Islands (Figure 2). Because of the long period of the fundamental mode of vibration of the structure (expected to be about $2.5 \mathrm{sec}$ during a strong-motion earthquake), it could be significantly affected by distant large earthquakes. In historic times, there have been two large events with magnitudes $M_{L}=7$ within $150 \mathrm{~km}$ of the platform, one in 1843 and the other in 1897 (Figure 2).

In addition, there was an earthquake of magnitude $M_{L}=6.1$ in November 1974 which was located approximately at the site of the platform (Figure 2). This event was recorded on an MO accelerograph (Hefford et al., 1979) at New Plymouth, about $60 \mathrm{~km}$ from the epicenter, which gave a peak reading of $0.046 \mathrm{~g}$. A plot of the intensity of shaking for this earthquake, as provided by the Seismological Observatory (1974) is given in Figure 3. 

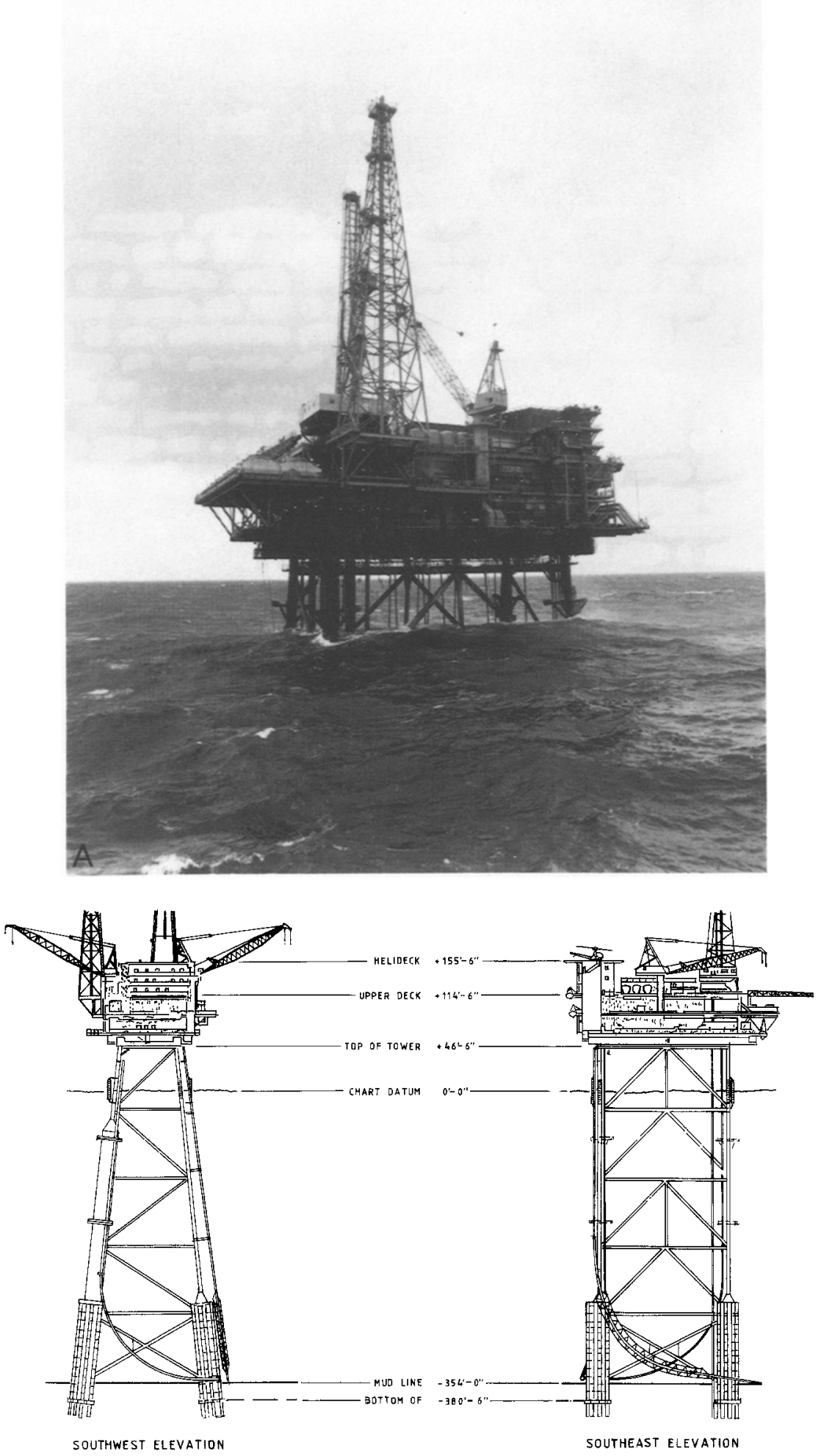

$\mathrm{B}$

Fig. 1. (A) View of Maui A Platform. (B) Elevations of platform. 
Smith (1976) calculates that, at the site of the Maui A Platform, the average return period for shaking of intensity MM VIII is about $100 \mathrm{yr}$.

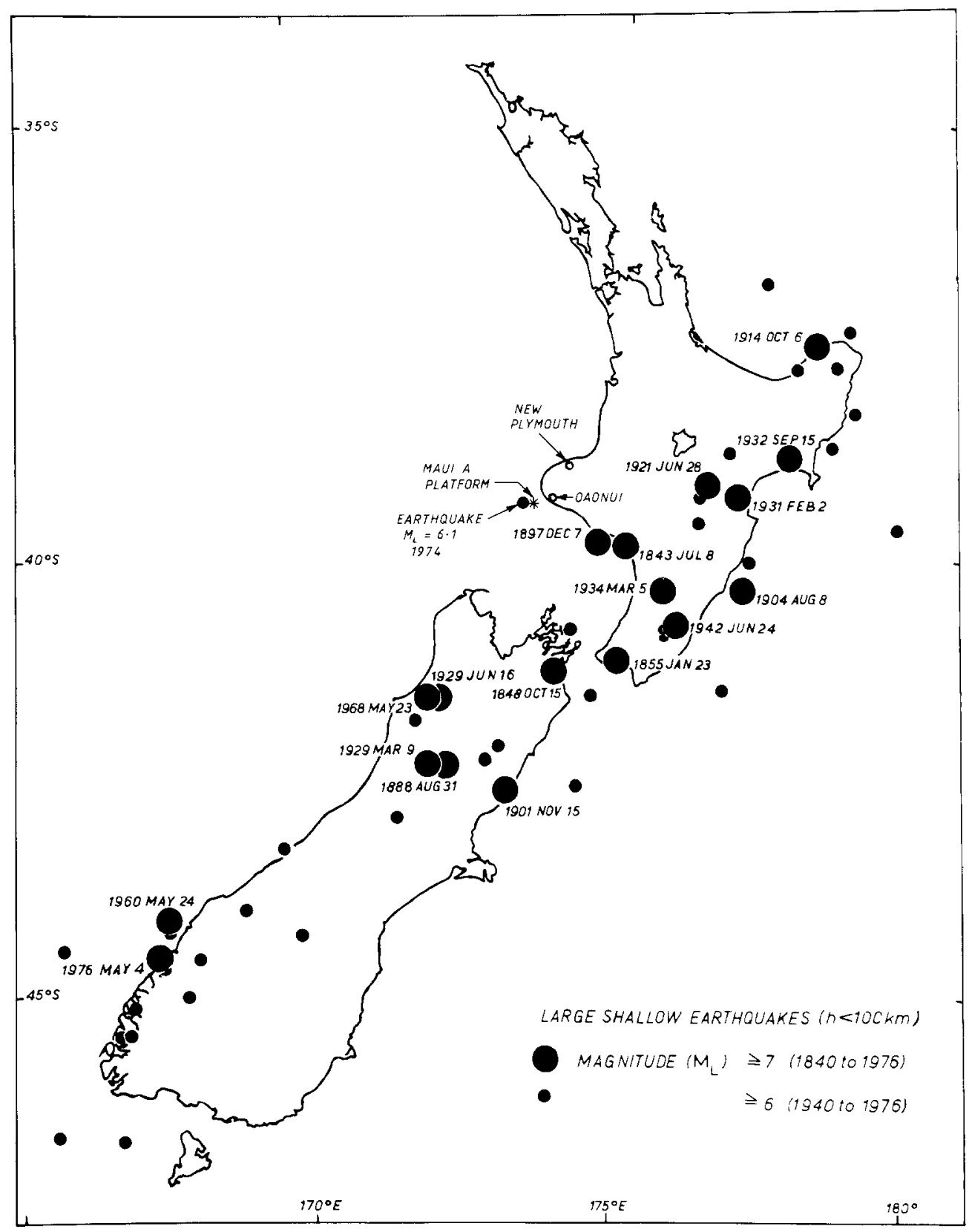

FIG. 2. Location of Maui A Platform and seismicity of New Zealand.

\section{History of Earthquake Instrumentation on Platform}

In response to requests from Shell BP Todd Ltd., two MO2 strong-motion recorders were installed in the workshop and generator room at the lowest level of the superstructure of the platform at the time of its commissioning in January 1978. Initially, these instruments triggered at a nominal vertical acceleration of $0.01 \mathrm{~g}$ but 
many visits to the site had to be made, as false triggerings resulted from vibrations generated during construction and operation of the platform and by wind action. Later, the instruments were made less sensitive, and site visits are now once every 4 months when only a few false triggerings are found. Only two small earthquakes

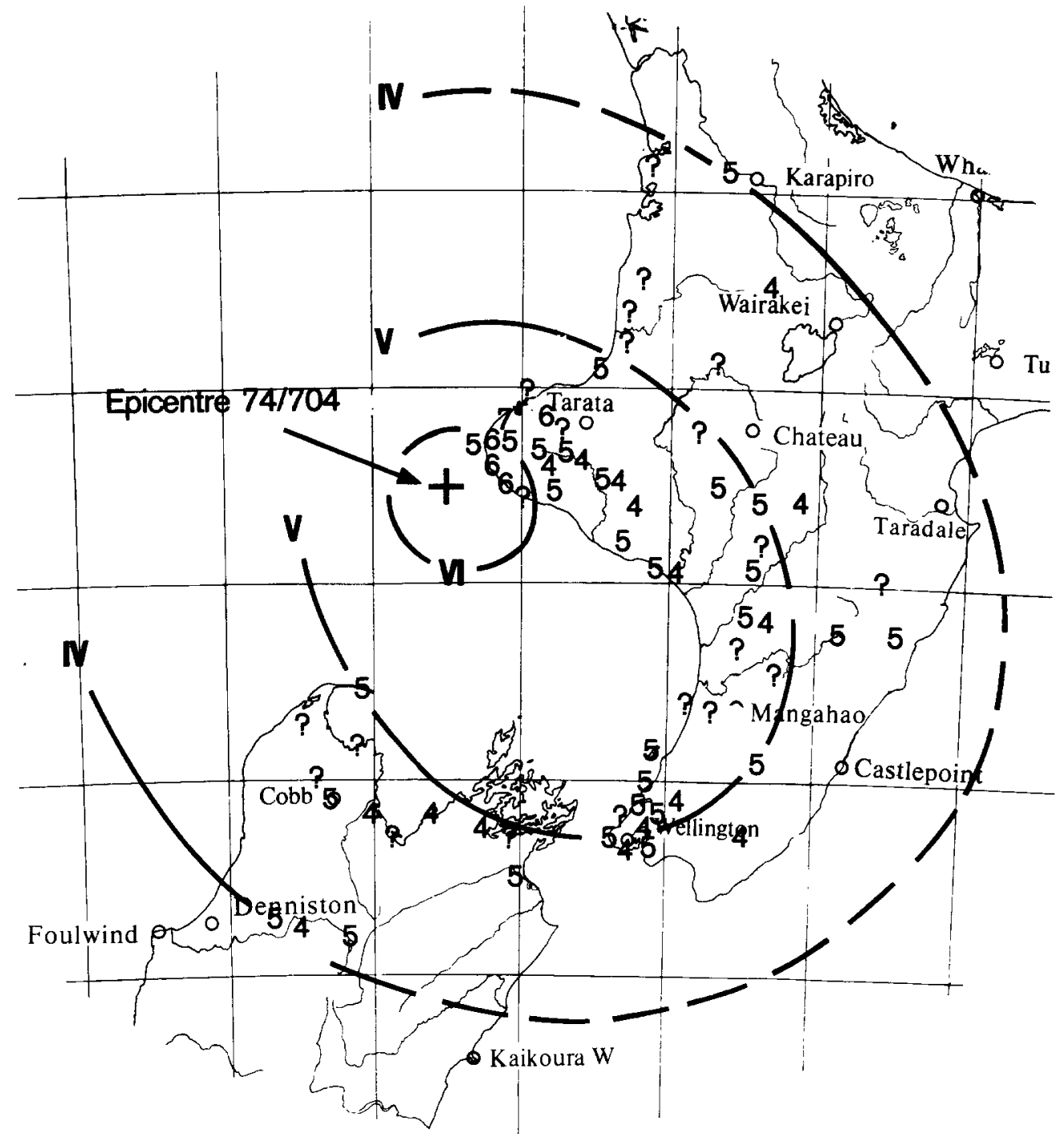

FIG. 3. Isoseismals of Modified Mercalli intensity of 1974 earthquake at site of Maui A Platform (Seismological Observatory, 1974).

have been recorded on the platform since the instruments were installed. Both of these events produced peak horizontal accelerations of about $0.025 \mathrm{~g}$ at the lowest level of the superstructure.

\section{Concept of Earthquake Alarm System}

While the strength of an earthquake attack could be monitored by records obtained from the strong-motion accelerographs on the platform, this would involve 
at least 2 days delay in processing the film records. It was decided, therefore, to install an earthquake alarm to give immediate warning in the central control room when a certain level of attack is reached. On the occurrence of an alarm, certain safety procedures prescribed by Shell BP Todd Ltd. would then be initiated by platform personnel.

The experience with the strong-motion recorders suggested that, because of the noisy vibration environment, any alarm should be designed to monitor only the response of the lower modes of the platform, since it is these which would produce the major contribution to the stresses in the platform tower during an earthquake. A filter would, therefore, need to be applied to eliminate the effects of higher frequencies. Since the design level of horizontal acceleration of the platform was $0.28 \mathrm{~g}$, it was decided that a deck acceleration of half this value, i.e., $0.14 \mathrm{~g}$, picked up in either of two orthogonal sensors in the horizontal plane, would be a satisfactory threshold level above which a warning is activated. The filter characteristics would be decided from a study of the ambient vibrations of the platform.

To further reduce the probability of a false alarm, it was decided to install a similar detection system at the production station on shore at Oaonui, $37 \mathrm{~km}$ from

TABLE 1

Modal Frequencies of the Maut A Offshore Platform Determined from Ambient Vibration

\begin{tabular}{ccc}
$\begin{array}{c}\text { Mode } \\
\text { No. }\end{array}$ & $\begin{array}{c}\text { TEsTs } \\
\text { Average } \\
\text { Frequency } \\
(\mathrm{Hz})\end{array}$ & $\begin{array}{c}\text { Observed } \\
\text { Variation } \\
\text { (\%) }\end{array}$ \\
\hline 1 & 0.449 & \pm 1 \\
2 & 0.507 & \pm 1 \\
3 & 0.660 & \pm 1 \\
4 & 0.955 & $\pm 1 / 2$ \\
5 & 1.135 & $\pm 1 / 2$ \\
6 & 1.35 & \pm 1 \\
\hline
\end{tabular}

the Maui A Platform, which would confirm the occurrence of an earthquake by a radio link. The preferred characteristics of the shore-based installation was the subject of considerable discussion with the consulting engineers, Edwards, Clendon, and Partners of Wellington, as a result of which it was decided that the radio link would be activated when a ground acceleration of $0.07 \mathrm{~g}$ horizontally was experienced on shore; the sensors would have the same filter characteristics as those on the platform, thus ensuring that the alarm would be activated only by those frequencies that would be most detrimental to the platform.

\section{Ambient Vibration Measurements}

Ambient vibration measurements were performed on the platform in order to determine the natural frequencies of its lower modes. A sensitive accelerometer was used to measure the low levels of acceleration $\left(10^{-4}\right.$ to $\left.10^{-3} \mathrm{~g}\right)$, and a digital spectrum analyzer was used to calculate and plot Fourier amplitude spectra at different locations within the superstructure of the platform. The natural frequencies were estimated from the location of the dominant spectral peaks; their relative amplitudes, together with the natural frequencies and mode shapes calculated from a dynamic model used in the design of the structure, were used to aid interpretation of the spectral peaks. 
The average values of the frequencies of the six lowest modes are given in Table 1 , together with the observed variations in the estimates from measurements made at different times and locations. In terms of their dominant motion and variation with height, these six modes can be described in order as the fundamental longitu-

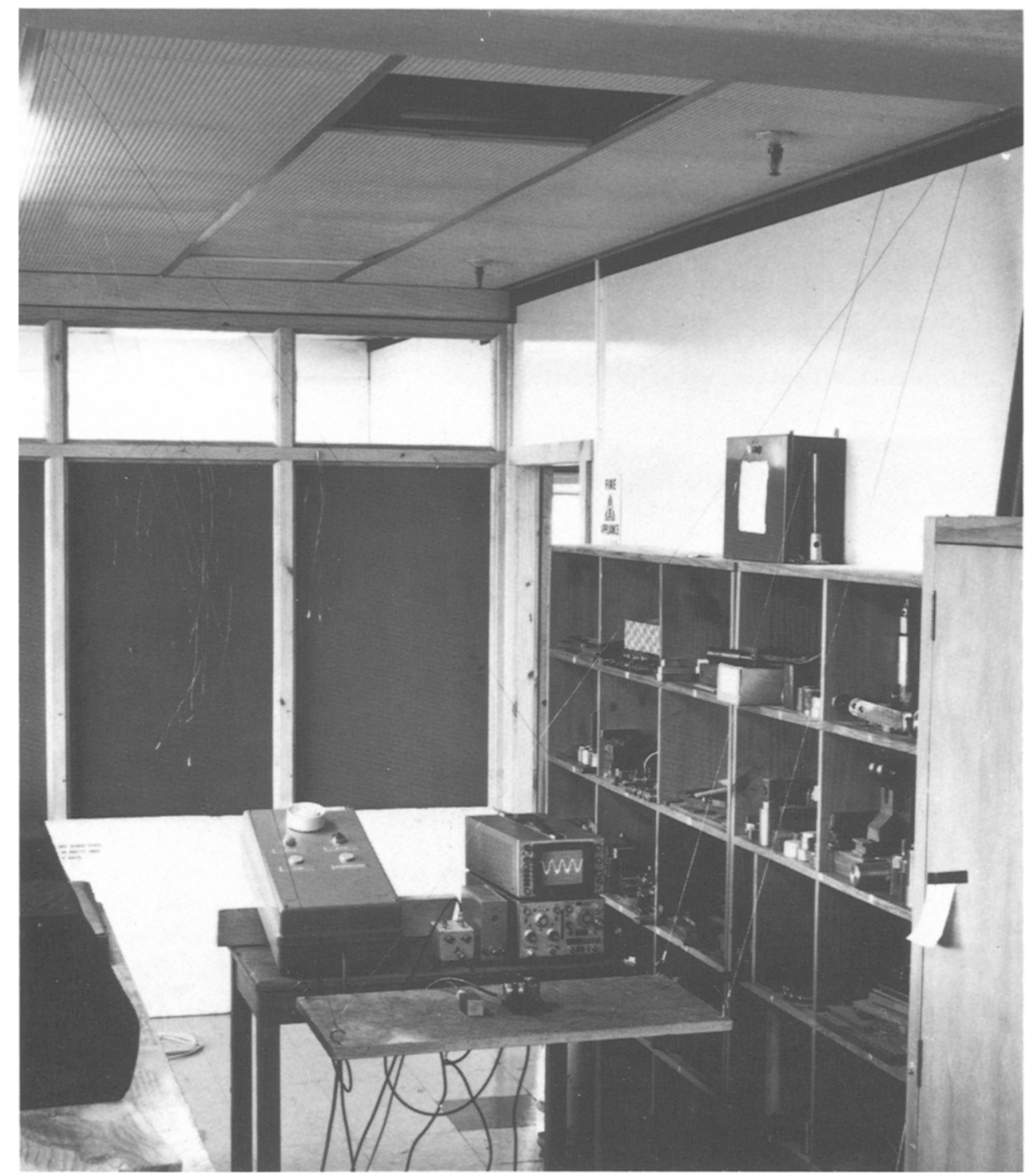

FIG. 4. Pendulum for calibrating accelerometers at low frequencies. (The horizontal platform in the foreground is suspended from the ceiling and swings at right angles to the paper.)

dinal, fundamental transverse, fundamental torsional, second transverse, second longitudinal, and second torsional. One interesting feature was that modes 1 and 6 each appeared consistently as closely spaced double peaks in the Fourier amplitude spectra, separated by approximately 0.015 and $0.03 \mathrm{~Hz}$, respectively. This phenomenon has been observed previously in ambient vibration measurements on an offshore platform and has been attributed to the interaction between an overall 
structural mode and a sloshing mode in a large liquid storage tank on the platform which have nearly coincident natural frequencies (Vandiver and Mitome, 1979). Calculations using a simple model indicate that this explanation is consistent also with the observed separation of the double peaks in the Maui A spectra.

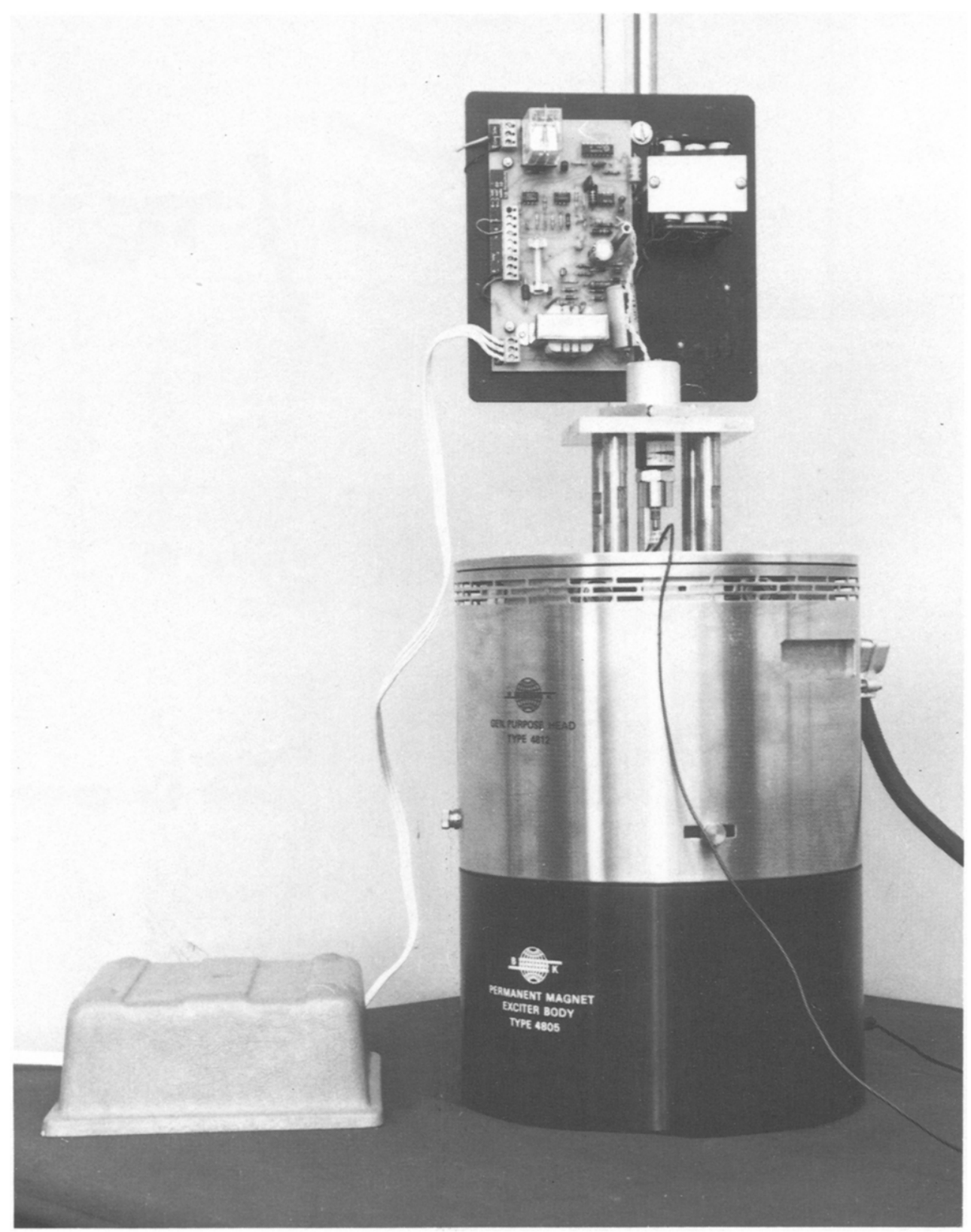

FIG. 5. Vertically driven shaking table set up to calibrate a single axis earthquake detector.

On the basis of the results in Table 1, it was decided to design the alarm so that the signal from the transducers passed through a filter which has a nominally flat frequency response over a bandwidth of 0.3 to $2 \mathrm{~Hz}$, which includes the six lowest 


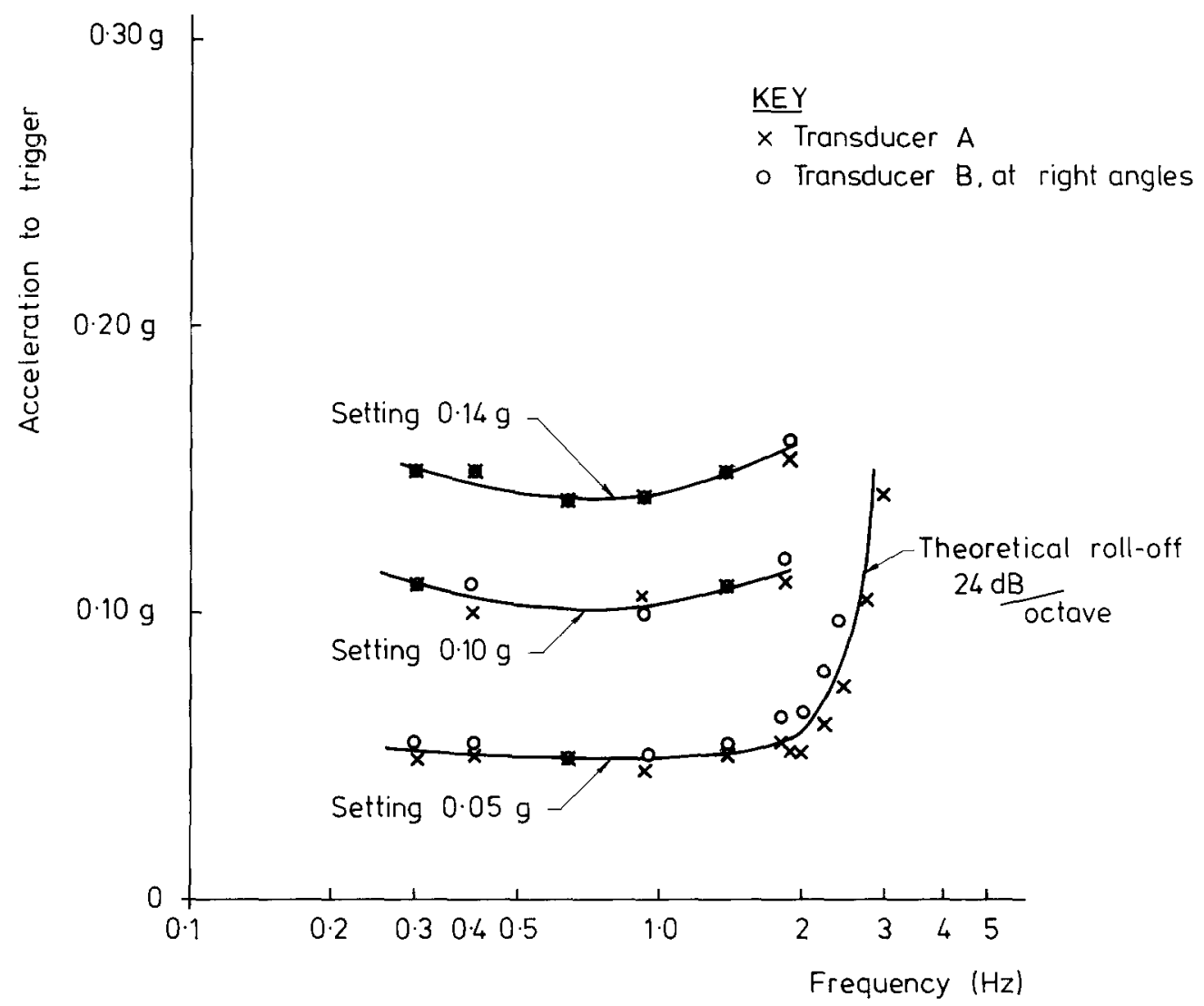

FIG. 6. Response of Maui A Platform sensor.

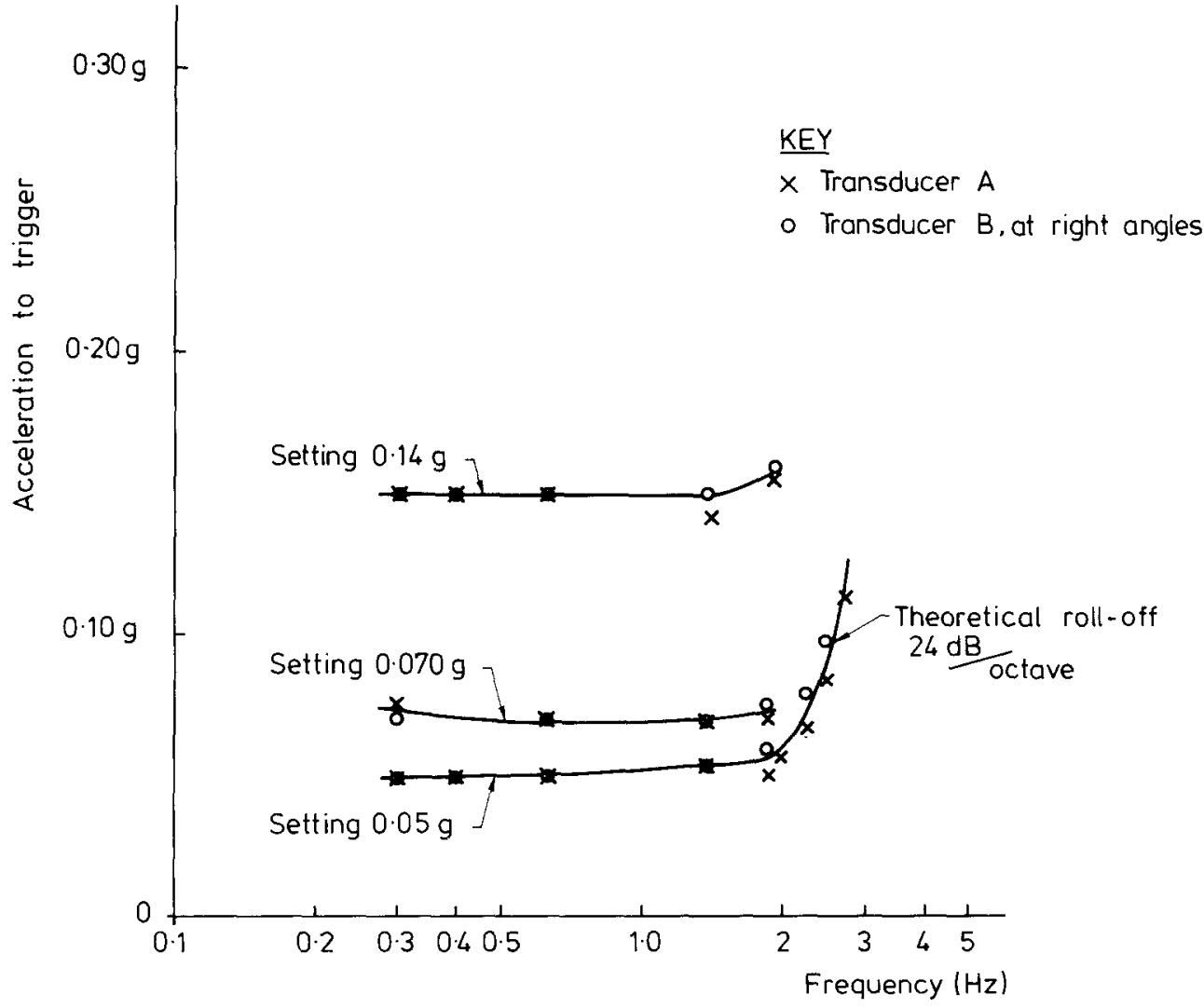

Fig. 7, Response of Oaonui shore-base sensor. 
modal frequencies, and which rolls off sharply at $24 \mathrm{~dB}$ per octave at higher frequencies.

\section{Calibration of Detectors}

Each detector was manufactured with a choice of three threshold settings: 0.14 , 0.10 , and $0.05 \mathrm{~g}$ for the platform, and $0.14,0.07$, and $0.05 \mathrm{~g}$ for the Oaonui Shore Base. They were set in the laboratory to the threshold settings of 0.14 and $0.07 \mathrm{~g}$ for the platform and shore base, respectively. Calibration was carried out using a pendulum suspended from the ceiling of the laboratory for the low frequencies (Figure 4) and a vertically-driven shaking table (Figure 5) at the higher frequencies, taking each of the four accelerometers, two for the platform and two for Oaonui, in turn. Sufficient power was not available in the vertical shaking table to confirm directly the desired roll-off above $2 \mathrm{~Hz}$ of $24 \mathrm{~dB}$ /octave for the settings above 0.05 $g$. However, the characteristics at the higher thresholds would be similar since the same low-pass filter is used. Results are shown in Figures 6 and 7.

\section{OPERATION}

The occurrence of an earthquake above the threshold level at either the platform or the shore base causes an audible alarm to be sounded at its location. In addition, a warning light appears at both locations through the radio link. The appearance of the platform warning light and the shore-base warning light together, which can be seen at both locations, is confirmation that an earthquake above the threshold level of the platform has taken place. The dual warning system was considered necessary to reduce the risk of false alarms.

\section{CoNCLUSION}

The alarm system was installed in August 1980. Up to the time of writing (April 1982), no earthquakes of significance have occurred in the area.

\section{ACKNOWLEDGMENTS}

The authors would like to thank the Board of Maui Developments Ltd. for permission to publish the results of the ambient vibration tests which were carried out in conjunction with P. R. E. Brown Ltd., Industrial Vibrations Consultant, of Auckland. The authors are also grateful for the cooperation of Solid State Equipment Ltd, of Lower Hutt, designers, and installers of the alarm system.

\section{REFERENCES}

Hefford, R. T., et al. (1979). The New Zealand strong-motion earthquake recorder network, Bull. NZ Natl. Soc. Earthquake Eng. 12, 256-263.

Seismological Observatory, DSIR. New Zealand Seismological Report 1974, Bulletin E-155, Wellington, New Zealand.

Smith, W. D. (1976). Statistical estimates of the likelihood of earthquake shaking throughout New Zealand, Bull. NZ Natl. Soc. Earthquake Eng. 9, 213-221.

Vandiver, J. K. and S. Mitome (1979). The effect of liquid storage tanks on the dynamic response of offshore platforms, J. Petroleum Tech. 31, 1231-1240.

Engineering Seismology Section

Physics AND EngINeERING Laboratory

DEPARTMENT OF SCIENTIFIC AND INDUSTRIAL

RESEARCH

Lower Hutt, New Zealand
Department of Civil Engineering California Institute of Technology Pasadena, California 91125 